\title{
Review Article \\ The Role of Toll-Like Receptors in Autoimmune Diseases through Failure of the Self-Recognition Mechanism
}

\author{
Mark Farrugia and Byron Baron \\ Centre for Molecular Medicine and Biobanking, Faculty of Medicine and Surgery, University of Malta, Msida MSD 2080, Malta \\ Correspondence should be addressed to Byron Baron; angenlabs@gmail.com
}

Received 10 January 2017; Revised 9 April 2017; Accepted 11 April 2017; Published 3 May 2017

Academic Editor: B. L. Slomiany

Copyright (c) 2017 Mark Farrugia and Byron Baron. This is an open access article distributed under the Creative Commons Attribution License, which permits unrestricted use, distribution, and reproduction in any medium, provided the original work is properly cited.

\begin{abstract}
Toll-like receptors (TLRs), part of the innate immune system that recognises molecular signatures, are important in the recognition of pathogenic components. However, when specific cellular contexts develop in which TLRs are inappropriately activated by selfcomponents, this may lead to sterile inflammation and result in the occurrence of autoimmunity. This review analyses the available data regarding TLR biochemistry, the specific mechanisms which are brought about by TLR activation, and the importance of these mechanisms in the light of any existing and potential therapies in the field of autoimmunity.
\end{abstract}

\section{Introduction}

The innate immune system relies on a limited number of germline-encoded receptors, known as pattern recognition receptors (PRRs), that have evolved to recognise molecular signatures [1]. Toll-like receptors (TLRs) are just one of several distinct classes of PRRs including Nod-like receptors (NLRs), C-type lectin receptors (CLRs), AIM2-like receptors (ALRs), RIG-I-like receptors (RLRs), and intracellular DNA sensors including cyclic GMP-AMP synthase (cGAS) [2,3], which recognise structures as diverse as flagellins, nucleic acids, saccharides (mainly mannose and lipopolysaccharide), peptidoglycans (such as lipoteichoic peptidoglycans), and lipoproteins. An adaptive immune response is triggered by the recognition of such antigens, mediated by proinflammatory cytokine production together with antigen-presenting cell (APC) stimulation.

TLRs are a family of type I transmembrane glycoproteins [4] consisting of a single transmembrane helix, which connects an extracellular ligand-binding domain to an intracellular signalling domain [5]. The extracellular domain can bind either directly to the ligand or to coreceptor-ligand complexes, and it then initiates ligand-mediated multimerisation of the receptor. TLRs generally are found as dimers, with most being homodimers, although TLR2 can be found preferentially as heterodimers either with TLR1 or with TLR6, even when a ligand is absent [6]. The intracellular signalling domains of TLRs have significant sequence similarity with the interleukin-1 receptor (IL-1) and are thus termed Toll/IL1R homology (TIR) domains [4]. TLRs are located either at the cell surface or in the endosomes. TLR1, TLR2, TLR4, TLR5, and TLR6 are expressed on the cell membrane, whereas TLR3, TLR7, TLR8, and TLR9 are localised mainly in the endosomal compartment [7]. TLR expression has been identified in various immune cells, including T-cells, B-cells, different subsets of dendritic cells, and macrophages $[8,9]$.

The TLR family can recognise a wide variety of bacterial, fungal, protozoan, and viral components, generally referred to as pathogen-associated molecular patterns (PAMPs). These TLR ligands can be grouped into three categories: lipids and lipopeptides (recognised by TLR2/TLR1, TLR2/TLR6, and TLR4), proteins (recognised by TLR5), and nucleic acids (recognised by TLR3, TLR7, TLR8, and TLR9). Different types of nucleic acid have their unique TLR, with viral double-stranded RNA (dsRNA) being recognised by TLR3, single-stranded RNA (ssRNA) being recognised by TLR7 and TLR8, and DNA containing unmethylated CG dinucleotides (whether from bacteria, viruses, or synthetic oligodeoxynucleotides, referred to as ODNs) being recognised by TLR9 $[1,10,11]$.

TLRs play an important role in both innate and acquired immune responses $[4,12,13]$. However, the inappropriate 
TABLE 1: TLRs involved in autoimmune disease with the ligands causing the immune reaction. (EDN: eosinophil-derived neurotoxin; Hsp: heat shock protein; HMGB1: high-mobility group box 1 protein.)

\begin{tabular}{ll}
\hline TLRs & Potential endogenous ligands \\
\hline TLR2 & HSP60, HSP70, HSP90 fragments, hyaluronic acid, versican, HMGB1, biglycan, EDN \\
\hline TLR3 & mRNA, dsRNA \\
\hline TLR4 & $\begin{array}{l}\text { HSP22, HSP60, HSP70, HSP72, HSP90, HMGB1, oxidised phospholipids, heparin sulfate, fibronectin, tenascin-C, } \\
\beta \text {-defensin 2, versican, hyaluronic acid, minimally modified-low-density lipoprotein, fibrinogen, lung surfactant protein A }\end{array}$ \\
\hline TLR7 & U1snRNP RNA, ssRNA \\
\hline TLR8 & ssRNA \\
\hline TLR9 & Hypomethylated CpG-DNA \\
\hline
\end{tabular}

TLR activation triggered by self-components brings about sterile inflammation and autoimmunity. Autoimmunity is the result of several mechanisms that are associated with the presence of autoreactive immune cell subsets and loss of immunological tolerance [9]. Organ-specific autoimmune diseases are the culmination of hereditary and environmental factors related to the failure of adaptive immune response regulation to self-antigens [14]. In fact, overexpression of PRRs was identified in the tissues of patients with organspecific autoimmunity, type 1 diabetes and Crohn's disease $[15,16]$.

Autoimmunity and infection have been linked together in several studies due to PAMPs being found in tissues after episodes of infection [17]. These are part of a substantial body of experimental data indicating that PRR activation on innate immune cells by either PAMPs or pathogens has the ability to dysregulate self-tolerance and subsequently activate autoreactive $\mathrm{T}$ - and B-cells.

However, TLRs are also known to recognise host-derived endogenous ligands which have undergone some form of change from their native state or accumulated excessively in nonphysiologic compartments [18]. Such ligands are referred to as damage associated molecular patterns (DAMPs) and are commonly released from damaged tissues or apoptotic cells such as high mobility group box 1 (HMGB1), saturated fatty acids, and amyloid $\beta$ and can result in chronic or acute inflammation [19-21]. However, under certain conditions TLRs can bind to such kind of self-molecules and as a result contribute to the development, progression, and resolution of autoimmune diseases [22]. A list of potential endogenous ligands and their respective TLRs can be found in Table 1.

In order to prevent TLR-induced inflammation, TLRactivated DCs cross-talk with and are suppressed by regulatory T-cells $\left(\mathrm{T}_{\text {regs }}\right)$, while the suppressive action of regulatory T-cells is blocked by APCs which have been stimulated through TLRs [23]. TLR stimulation can conversely be inhibited by cytokines such as interleukin- (IL-) 10 secreted by regulatory T-cells $[24,25]$. Different subsets of $\mathrm{T}_{\text {regs }}$ exist and their impairment has been reported in a number of human autoimmune conditions, including oral tolerance [26].

\section{TLR Signalling Pathways}

The stimulation of TLRs by the respective ligands results in the recruitment of downstream adaptor molecules, such as myeloid differentiation factor 88 (MyD88), myeloid
Toll/interleukin- (IL-) 1 receptor- (TIR-) domain-containing adaptor-inducing interferon- $\beta$ (TRIF a.k.a. TIR-domaincontaining molecule 1; TICAM1), TIR-associated protein (TIRAP a.k.a. MyD88 adaptor-like; Mal), TRIF-related adaptor molecule (TRAM), or sterile $\alpha$ - and armadillo-motif containing protein (SARM) $[6,27,28]$, which trigger a number of downstream molecules activating signalling cascades converging at the nuclear factor- $\mathrm{kB}(\mathrm{NF}-\mathrm{kB})$, interferon (IFN) response factors (IRFs), and mitogen-activated protein (MAP) kinases. These transcription factors induce the transcription of various immune response genes, including inflammatory cytokines (such as interleukin- (IL-) 6, IL12 , IL-23, and tumour necrosis factor $\alpha(\mathrm{TNF}-\alpha))$, stimulatory immune cytokines, chemokines, and costimulatory molecules [29, 30] (Figure 1).

TLRs specifically recruit and signal via TRIF, TIRAP, TRAM, or direct MyD88 activation to produce a different response, despite this recruitment being always through heterotypic TIR-TIR interactions. More specifically, except for TLR3, MyD88 is utilised by all TLRs and activates NF-kB and mitogen-activated protein kinases (MAPKs) to induce the genes encoding inflammatory cytokines [31]. TIRAP acts as a sorting adaptor by recruiting MyD88 to TLRs at the cell surface. One study has also shown that TIRAP is involved in endosomal TLR signalling (such as TLR9) by binding to different lipids $[32,33]$. The recruitment of TRIF to TLR3 and TLR4 promotes an alternative pathway to that of MyD88 [34]. Interestingly, TRAM has been shown to be recruited specifically to TLR4 but not TLR3 and serves as the link between TRIF and TLR4 [35]. Thus, depending on what adaptor protein is used, one can divide TLR signalling into two pathways: MyD88-dependent and TRIF-dependent pathways.

In the MyD88-dependent pathway, TLR binding leads to MyD88 forming a complex with IRAK kinases [36], such that IRAK4 activates IRAK1 [37, 38]. IRAK1 then associates with TRAF6, a RING-domain E3 ubiquitin ligase, which polyubiquitinates and activates TAK1 $[39,40]$. This results in the activation of the NF-kB and MAPK pathways. NF$\mathrm{kB}$ is activated through the IKK complex (composed of the $\mathrm{IKK} \alpha$ and IKK $\beta$ catalytic subunits and the IKK $\gamma$ regulatory subunit), which phosphorylates the NF-kB inhibitory protein $\operatorname{IkB} \alpha$, allowing the translocation of NF-kB to the nucleus inducing the expression of proinflammatory genes. The MAPK pathways are induced through ERK1/2, p38, and JNK, which mediate activation of AP-1 and regulate inflammatory responses [2, 41]. 


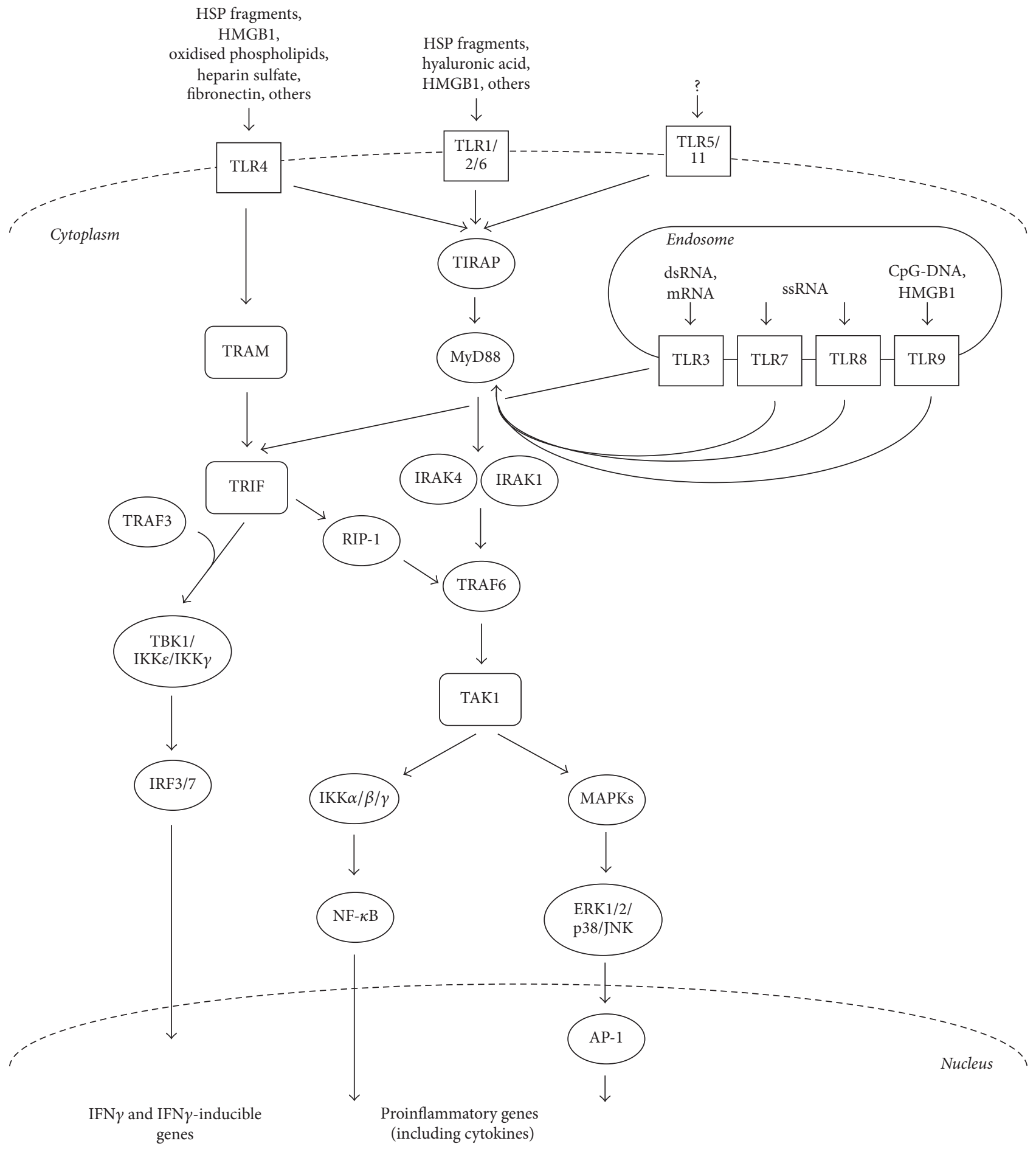

FIGURE 1: TLR signalling pathways. The two main pathways by which TLR signalling occurs upon stimulation by their ligands. These pathways are characterised depending on which of the adaptor molecules MyD88 or TRIF are involved. These signalling cascades result in the activation of NF-kB, IRFs, and MAP kinases, which promote the transcription of various immune response genes, including inflammatory cytokines and IFN $\gamma$-related genes. (AP-1, activator protein 1; ERK, extracellular signal-regulated kinase; IKK, inhibitor of kappa light polypeptide gene enhancer in B-cell kinase; IRAK, IL-1 receptor-associated kinase; JNK, c-Jun N-terminal kinase; MKK, MAPK kinase; RIP1, receptor interacting protein 1; TAK, transforming growth factor-activated kinase; TBK1, TANK-binding kinase 1; TRAF, tumour necrosis factor receptor-associated factor.) 
In the TRIF-dependent pathway, once TRIF is activated by either TLR3 or TLR4, it binds to TRAF6 via the recruitment of RIP-1 kinase, which leads to the activation of TAK1. This results in the NF-kB and MAPKs induction of inflammatory cytokines as discussed above. Meanwhile, TRIF also activates TRAF3 which recruits IKK-related kinases (TBK1 and IKKe) and IKK $\gamma$ for IRF3 phosphorylation, which translocates into the nucleus inducing the expression of type I IFN genes $[2,41]$. On the other hand, TRAF3 binds to the MyD88 complex causing its degradation and leading to TAK1 activation. This implies that TRAF3 promotes the TRIFdependent pathway via direct activation, while concurrently inhibiting the MyD88-dependent pathway.

\section{Nucleic-Acid-Sensing TLRs in Autoimmune Disease}

The nucleic-acid-sensing TLRs are endosomal and consist of TLR3 (which recognises viral dsRNA [42]), TLR7 and TLR8 (which recognise viral ssRNA [43-45]), and TLR9 (which recognises bacterial and viral unmethylated $\mathrm{CpG}$-containing DNA motifs [46]). TLR3 signalling is distinguished from the rest in that it signals via the adaptor TRIF, while TLR7, TLR8, and TLR9 signal through the adaptor molecule MyD88 [47]. TLR3 also binds to self-mRNA [48].

The restricted access to these TLRs is one mechanism by which to prevent them from being aberrantly activated by self-nucleic acids (as those released by apoptotic cells), which could bring about autoimmune diseases. However, the dysregulation of TLR7, TLR8, and TLR9 plays a major role in numerous autoimmune diseases.

Studies show that immune complexes (ICs) composed of DNA and the immunoglobulin G ( $\operatorname{IgG})$ that recognises them stimulate $\mathrm{pDCs}$ in humans to produce IFN $\alpha[11,20$, $49,50]$ and the production of autoantibodies in mice via a process which involves TLR7 and/or TLR9 [51, 52]. Such ICs containing self-nucleic acids are recognised via the FcR $\gamma$ IIa receptor expressed on the surface of plasmacytoid dendritic cells (pDCs; innate immune cells) [53]. Once antibodies are captured, the FcR allows ICs to enter pDC and activates the endosomal pathway [54]. In the endosome, the nucleic acid component of the IC is likely released by the low $\mathrm{pH}$. The nucleic acids then trigger TLR7 or TLR9 which brings about the maturation of the $\mathrm{pDC}$ and induces IFN $\alpha$ production $[50,54,55]$.

The trafficking of nucleic-acid-sensing TLRs from the endoplasmic reticulum to endosomes for ligand recognition as well as their nucleic acid-sensing function is controlled by the multipass transmembrane protein Unc93B1 [56]. This protein is also involved in the localisation regulation of nucleic-acid-sensing TLRs, with studies presenting evidence of competition between TLR7 and TLR9 for Unc93B1dependent trafficking, where TLR9 predominates due to a higher affinity for Unc93B1 than TLR7 [56-59]. Thus, Unc93B1 regulates excessive TLR7 activation by balancing TLR9 to TLR7 trafficking. The mutation of Unc93B1 by an amino acid substitution (D34A) resulted in a phenotype which presents TLR7-hyperreactivity together with TLR9-hyporeactivity, which was linked to systemic lethal inflammation, known to be TLR7-dependent [59]. It is thus hypothesised that in some autoimmune diseases deficiency of either TLR8 or TLR9 will result in decreased competition of these endosomal TLRs to bind to Unc93B1, making TLR7 more available and resulting in higher TLR7 trafficking and response. This manifests itself as autoimmune phenotypes [60]. Consequently, altering the TLR7 to TLR9 balance can be envisioned as a potential regulatory mechanism in the context of autoimmunity [59].

TLR7 activity regulation appears to be cell type dependent, with the TLR7 response being controlled by TLR8 on dendritic cells and by TLR9 on B-cells. This has been shown using the TLR7 agonist R848 on TLR8 ${ }^{-/-}$and TLR8/9 ${ }^{-/-}$ derived from bone marrow (which produced significantly higher amounts of IFN $\beta$ mRNA (at $4 \mathrm{~h}$ ), IL-6, and TNF, compared with WT or TLR9 ${ }^{-/-}$cells) and TLR8/9 $9^{-/-}$and TLR9 $^{-/-}$B-cells (which presented significant CD69 and CD86 upregulation, when compared to TLR8 ${ }^{-/-}$or WT B-cells) [60]. Concomitantly, TLR8 ${ }^{-/-}$and TLR8/9-/- Bcells presented a significant increase in TLR7 $\mathrm{mRNA}$ levels compared to WT or TLR9 ${ }^{-/-}$cells. Furthermore, TLR8 $/ 9^{-/-}$ mice had a significantly higher percentage of activated and memory CD4 and CD8 T-cells compared to WT or TLR9 ${ }^{-/-}$ mice, while in $\mathrm{TLR}^{-/-}$mice the values were only significantly higher when compared to WT mice [60].

\section{Protein-Sensing TLRs in Autoimmune Disease}

TLR2 and TLR4, which are both cell surface TLRs, are involved in regulating Th immune responses. In fact, it was shown that, depending on which TLRs are ligated, the Th responses can be skewed towards a Th1 or Th2 cytokine profile [61]. This is in contrast with a previous model in which Th2 differentiation was driven forward without any TLRmediated signals. Despite the promotion of Th2 responses (and allergic inflammation) in some contexts by low-doses of inhaled LPS [62], generally TLR4 stimulated by LPS brings about the maturation of DCs associated with strong Thl-type responses as a consequence of IL-12 release [63]. Moreover, both TLR2 and TLR4 were found to be involved in regulating $\gamma \delta$ T-cell [64] and CD4+ T-helper 17 (Th17) [65] production of IL-17. More specifically, in vitro studies showed that in $\gamma \delta$ T-cells expansion and IL-17 production are promoted by the activation of TLR4 [65]. TLR2 signalling could also stimulate naive cells to expand and undergo polarisation towards the Th17 lineage [65] and provide $\mathrm{CD} 4^{+}$and $\mathrm{CD} 8^{+} \mathrm{T}$-cells with a costimulatory signal $[66,67]$.

TLR2 and TLR4 have been shown to also respond to endogenous heat-shock proteins $[68,69]$. Clinical observations confirm that HSPs are involved in the regulation of some autoimmune disease such as autoimmune arthritis, type 1 diabetes, atherosclerosis, multiple sclerosis, and others [70].

\section{Role of TLRs in Autoantibody Production}

TLRs are known to play a critical role in autoantibody production because genetic mutations which lead to some 
deficiency in either TLR7, TLR9, or MyD88 most commonly also lead to a reduction in autoantibody production, while an increase in TLR7 production generally leads to a susceptibility towards developing autoimmune diseases [71]. Moreover, the engagement of B-cell receptor by chromatin-IgG complexes and TLR9 signalling were shown to be essential and act synergistically in the activation of autoreactive B-cells in vitro [51].

However, it is difficult to gauge the direct contribution of TLR signalling in B-cells in vivo since the activation of both DCs and plasmacytoid DCs is brought about by the same TLR ligands and play just as important roles in the pathogenesis of autoimmune diseases [20]. Furthermore, TLRs are expressed by a variety of cell types that have the ability to regulate the functions of B-cell through the activation of their TLRs. So far evidence seems to suggest that the intrinsic TLR signalling of $\mathrm{B}$-cells is a requirement for the production of autoantibodies in vivo [72-74].

\section{Spectrum of TLR Action in Autoimmune Disease Contexts}

The involvement of TLRs in early inflammatory immune responses is responsible for their ability to develop autoreactive B- and T-cells. There is now a well-established link between a variety of infections and autoimmune diseases, both in animal models and in the clinical setting. Such autoimmune responses are thought to be the result of molecular mimicry of the pathogen-derived antigens to self-antigens or a form of nonspecific activation of the innate immune system (through loss of immunological tolerance) that results in the production of T-cells and antibody responses specific to self-antigens, implicating TLRs in numerous autoimmune diseases. Here we would like to point out three disease settings.

6.1. TLRs in Rheumatoid Arthritis. Several of the risk alleles linked to rheumatoid arthritis (RA) are associated with immune regulation such as $\mathrm{NF}-\kappa \mathrm{B}$-dependent signalling, $\mathrm{T}$ cell stimulation, activation, and functional differentiation. This suggests that these immunologic pathways are amongst the key modulators of the development of the autoimmune inflammation in RA $[75,76]$. Through the use of human synovial membrane cultures from patients with RA it has been shown that expression of TLR2 and TLR 4 in conjunction with the release of endogenous ligands to these two TLRs may play a role in inflammation and damage to joints in RA patients [77]. The alarmin heterogeneous nuclear ribonucleoprotein (hnRNP) was also found to play a role in human RA and pristane-induced arthritis in rats. This RNA- and DNAbinding complex binds to most nuclear antigen-specific $\mathrm{B}$ and T-cells in systemic autoimmune diseases. Moreover hnRNP was shown to activate APCs causing arthritis mediated by TLR7 and TLR9, which can then activate harmful T-cells [78].

6.2. TLRs in Type 2 Diabetes Mellitus. Innate immune responses leading to Type 2 Diabetes Mellitus (T2DM) can be initiated by adipose tissue inflammation, as has been shown through LPS-treatment of adipocytes which showed significant increase in TLR2, TRAF-6, and NF- $\kappa$ B levels as well as increased secretion of potentially diabetogenic proinflammatory cytokines. Similarly, abdominal subcutaneous adipose tissue isolated from diabetic patients presented increases in the expression of TLR2, MyD88, TRAF6, and $\mathrm{NF}-\kappa \mathrm{B}$. It has thus been proposed that obesity may increase proinflammatory cytokines in the host and subsequently increase the risk of T2DM [79]. TLR4 is thought to be an important mediator of obesity and insulin resistance because of its activation by saturated fatty acids and LPS, known to cause insulin resistance in adipose tissue amongst others. Obesity is associated with insulin resistance and is considered to be amongst the major risk factors in the development of T2DM and cardiovascular diseases. Thus, TLR4 is being considered as a potential therapeutic target in the treatment of these metabolic diseases [4].

6.3. TLRs in Other Diseases Not Generally Classified as Autoimmune. Two widespread diseases that are considered to have an autoimmune component are atherosclerosis and cancers. Both have now been shown to display TLR-directed responses. In the case of atherosclerosis a link has been found with TLR-induced IFN $\alpha[18,80,81]$, while, in cancer, the cells dying from chemotherapy release endogenous molecules that bring about an innate immune response following TLRmediated recognition, which has been found to be critical for cancer elimination [82].

\section{Therapeutic Application of TLR Regulators}

TLR signalling is negatively regulated by a number of molecules, which act through a variety of mechanisms in order to prevent or control excessive immune responses. In autoimmunity and inflammatory diseases these processes could be nonfunctional, dysregulated, or simply not enough to overcome the TLR signalling in place. In an attempt to control aberrant immune responses both natural and synthetic negative regulators targeting each of the key molecules in the TLR signalling pathways have been identified. In fact, blocking the activation signal at the TLR level rather than targeting individual PAMPs or DAMPs is a more preferred and effective therapeutic approach since sterile inflammation contexts tend to be induced by similar signalling pathways and there may be multiple autoimmunity inducing peptides following tissue injury.

Cationic peptides (such as LL-37 or polymyxin), for example, are known to facilitate the uptake of self-DNA by plasmacytoid dendritic cells ( $\mathrm{pDCs}$ ) to activate TLR9 signalling and can lead to preferential localisation in the early endosomes of pDCs [81, 83], leading to significant IFN $\alpha$ production $[83,84]$. One context in which this applies is psoriasis, in which the DNA is not transported in the form of an IC but associated with the antimicrobial cationic peptide, LL-37 [81]. Synthetic ligands of TLRs that effectively regulate innate and adaptive immune responses thus have the potential of being a new class of therapeutic molecules [85].

Some of these agents act directly on the TLRs themselves. Vitamin D3 has been shown to downregulate TLR2 and TLR4 
expression on monocytes [86]. Endosomal TLRs like TLR7, TLR8, and TLR9 can be inhibited by Chloroquine and related compounds, which act as antagonists that specifically target and inhibit signalling through these TLRs [87-91]. Nucleic acid-binding polymers are another class of endosomal TLR inhibitors which recognise ssRNA, dsRNA, or hypomethylated DNA and bind to them, thus inhibiting nucleic acidmediated activation of these TLRs [30]. 9-Benzyl-8-hydroxy2-(2-methoxyethoxy) adenine on the other hand acts as a TLR7 agonist, which induces hyporesponsiveness or tolerance, thus still inhibiting TLR7 activation [92]. Research in such agonists could lead the way to the synthesis of drugs which could inhibit TLR overactivation while still sparing the side-effects related to total inhibition of these pathways.

At the protein level activation of the MyD88-dependent pathway is suppressed by the synthetic inhibitor ST2825, which is a heptapeptide analog specifically designed to inhibit MyD88 dimerisation, thus interfering with the recruitment of IRAK1 and IRAK4 by MyD88 [93]. Compound 4a is also responsible for inhibiting the MyD88 dependent pathway activation by interfering with the interaction between MyD88 and the TIR domains of TLRs [94]. Other inhibitors of MyD88 include Suppressor of Cytokine Signalling 1 (SOCS1) and the E3 Ubiquitin Protein Ligase Cbl-b. Further down the pathway IRAK1 and IRAK4 are targeted by RO0884 which acts as a dual inhibitor of both these protein kinases resulting in the blocking of proinflammatory cytokine production [95]. TRAF6 is targeted by a number of inhibitory molecules such as Tumour Necrosis Factor Inducible Protein A20 (A20), Ubiquitin Specific Peptidase 4 (USP4), Ubiquitin-SpecificProcessing Protease CYLD (CYLD), TRAF Family Member Associated NF- $\kappa$ B Activator (TANK), Tripartite Motif Containing Protein 38 (TRIM38), and Small Heterodimer Partner (SHP) [96-98]. TAK1 activation is inhibited by Tripartite Motif Containing 5 (TRIM5; TRIM30a in mouse) and A20 [99]. In addition to these signalling molecules, the transcription factor NF- $\kappa \mathrm{B}$ is suppressed by B-Cell Lymphoma 3 -Encoded Protein (Bcl-3), NF- $\kappa$ B Inhibitor Delta (IkBNS), Nuclear Receptor Related 1 (Nurr1), Activating Transcription Factor 3 (ATF3), and PDZ and LIM Domain Protein 2 (PDLIM2) [100].

Activation of the TRIF-dependent pathway is suppressed by Sterile Alpha and TIR Motif Containing 1 (SARM) and a splice variant of the adaptor TRAM called TAG [101103], both acting as direct TRIF inhibitors. TRAF3 activation is negatively regulated by Suppressor of Cytokine Signalling 3 (SOCS3) and Deubiquitinating Enzyme A (DUBA) [104]. SOCS3 is itself upregulated by high molecular weight hyaluronan (HA900), making it also a key molecule in regulating TRAF3 activation [105]. IRF3 activation is negatively regulated by Peptidylprolyl Cis/Trans Isomerase, NIMA-Interacting 1 (PIN1) and Ubiquitin Protein Ligase E3C (UBE3C or RAUL) [100]. (Figure 2).

At the RNA level, micro-RNAs (miRNAs) such as miR146a, miR-199a, miR-155, miR-126, miR-21, miR-29, miR$148 / 152$, and miR-466l regulate the stability of mRNAs that encode TLR signalling molecules [98]. Furthermore, the stability of mRNAs encoding cytokines are regulated by
Regnase- 1 and the zinc finger protein Tristetraprolin (TTP) $[41,98]$. It was shown that, after being treated with a variety of TLR ligands, Regnase-1-deficient macrophages produce large amounts of cytokines and increased autoantibody production in Regnase-1-deficient mice [106].

One of the more interesting areas of research for therapeutic application of TLR modulators is the development of atypical, nonstimulatory DNA sequences called immuneregulatory DNA sequences (IRS) to regulate immunestimulatory ligands of TLR7 and TLR9 as well as altogether inhibiting TLR7 and TLR9 stimulation [107]. Ligands of TLR9 include CpG-containing immune-stimulatory sequences (CpG-ISS) of diverse origin, including sequences of viral origin, $\mathrm{CpG}$ sequences which have been mutated, or mammalian telomere TTAGGG motif repeats [107-115].

A kind of TLR7 inhibitor (exemplified by IRS 661) acted specifically on mouse splenocytes to reduce their response to the TLR7 agonist R848, while having no effect on the response to a CpG-ISS, which is a TLR9 agonist. It also efficiently blocked antiribonucleoproteins (RNPs) but not anti-DNA-induced IFN $\alpha$, indicating the role of TLR7 in this process. On the other hand, the TLR9 inhibitor IRS 869 was effective in inhibiting TLR9 activation by CpGISS, while having no effect when the TLR7 ligand R848 was used to activate the splenocytes, proving that antidsDNA-induced IFN $\alpha$ is TLR9-dependent. A newer type of inhibitor, exemplified by IRS 954 (derived by combining the three $5^{\prime}$ residues from the TLR7 inhibitor IRS 661 (TGC) with the TLR9 inhibitor IRS 869), could significantly inhibit splenocyte activation by ligands to TLR7 and TLR9 [50]. This IRS 954 was shown to strongly inhibit IFN $\alpha$ production by pDCs in response to ICs containing DNA or RNA. R848, through its mechanism of being a TLR7 agonist, was also found to induce production of IFN- $\gamma$ in invariant NKT cells, which can alleviate allergic inflammation [116].

TLR modulators and inhibitors offer great promise with high selectivity and effectiveness when tested out in animal model for most autoimmune diseases. However it is important to recall when attempting to test inhibitors targeting TLRs and their signalling pathways for therapeutic applications using disease models in mice that humans and mice have different expression and distribution of TLRs and that any responses produced are just as different; for example, in humans, treatment with a TLR9 ligand produces a response dominated by the IFN $\alpha$ pathway [117119] (stimulating numerous IFN-regulated genes elevated in lupus $[120,121])$, while in mice TLR9 activation leads to the expression of proinflammatory cytokines such as IL-6, IL-12, or TNF- $\alpha$ via macrophage and myeloid DC activation.

\section{Conclusion}

TLRs have been shown to cover a much greater recognition repertoire than originally thought and a number of autoimmune diseases are either initiated or aggravated by TLR dysregulation. Thus further work in the field will definitely focus on uncovering more pieces to this ever growing signalling puzzle providing researchers and clinicians a clearer 


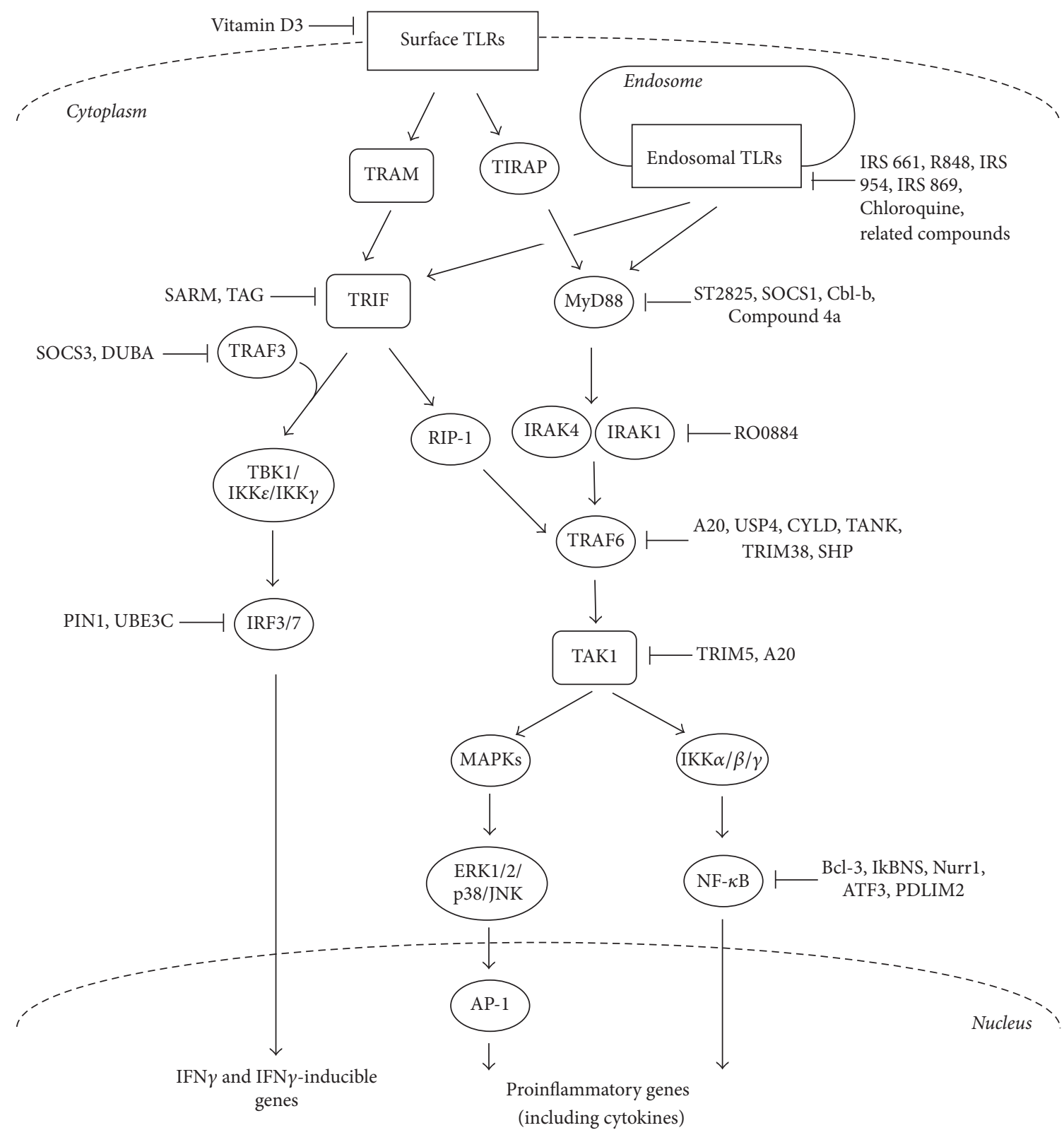

FIGURE 2: TLR signalling inhibitors. The regulation of TLR signalling has been achieved through the application of both natural and synthetic inhibitory molecules, which target each of the key molecules in the TLR signalling pathways, acting through a wide range of mechanisms. (AP-1, activator protein 1; ATF, activating transcription factor; ERK, extracellular signal-regulated kinase; IKK, inhibitor of kappa light polypeptide gene enhancer in B-cell kinase; IRAK, IL-1 receptor-associated kinase; JNK, c-Jun N-terminal kinase; MKK, MAPK kinase; RIP1, receptor interacting protein 1; TAB, transforming growth factor-b-activated kinase 1/MAP3K7-binding protein; TAK, transforming growth factor-activated kinase; TRAF, tumour necrosis factor receptor-associated factor); A20, Tumour Necrosis Factor Inducible Protein A20; ATF3, Activating Transcription Factor 3; Bcl-3, B-Cell Lymphoma 3-Encoded Protein; Cbl-b, E3 Ubiquitin Protein Ligase Cbl-b; CYLD, Ubiquitin-Specific-Processing Protease CYLD; DUBA, Deubiquitinating Enzyme A; HA900, high molecular weight hyaluronan; IkBNS, NF$\kappa$ B Inhibitor Delta; Nurrl, Nuclear Receptor Related 1; PDLIM2, PDZ and LIM Domain Protein 2; PIN1, Peptidylprolyl Cis/Trans Isomerase, NIMA-Interacting 1; SARM, Sterile Alpha and TIR Motif Containing 1; SHP, Small Heterodimer Partner; SOCS1, Suppressor of Cytokine Signalling 1; SOCS3, Suppressor of Cytokine Signalling 3; TAG, splice variant of the adaptor TRAM; TANK, TRAF Family Member Associated NF- $\kappa$ B Activator; TRIM5, Tripartite Motif Containing 5; TRIM38, Tripartite Motif Containing Protein 38; UBE3C, Ubiquitin Protein Ligase E3C; USP4, Ubiquitin Specific Peptidase 4. 
picture of the actual signalling pathways and viable, effective, druggable targets.

In fact a number of clinical trials are currently underway. These include antagonists of TLR4, such as TLR4 targeted monoclonal antibody NI-0101, by Novimmune, which has several potential applications including asthma and rheumatoid arthritis and is the first antibody for TLR4 to pass Phase I clinical trials for safety and tolerability [122]. Antagonists of the endosomal TLRs (specifically TLR7, TLR8, and TLR9) are also being studied, such as IRS954 by Dynavax and IMO3100 by Idera, who have published results from their Phase II trials for this drug [123], amongst others. As indicated by such clinical trials, the inhibition of aberrant TLR signalling induced by endogenous DAMPs or exogenous PAMPs has high potential as a viable therapeutic approach in humans for the treatment of autoimmune diseases.

The insight from such TLR signalling research should also direct the medical field to rethink the classification of some diseases or the way in which they are treated. Over the past decade lots of new components and interactions have been discovered and it is plausible to postulate that there is much more to be discovered. This being said, the position of the classification, development, and treatment of complexes or multifactorial diseases should also be reconsidered to include elements of autoimmunity.

Moreover, we are now starting to gain the ability to modulate specific TLR activity, which should be used to the benefit of patients suffering from such TLR-dependent autoimmune diseases. In order to achieve this goal, more studies on the inhibitors mentioned above and others are required in order to provide alternatives to the current limited therapeutic options, providing a long-term solution, with reduced off-target effects.

\section{Conflicts of Interest}

The authors declare that there are no conflicts of interest regarding the publication of this paper.

\section{References}

[1] C. A. Janeway Jr. and R. Medzhitov, "Innate immune recognition," Annual Review of Immunology, vol. 20, pp. 197-216, 2002.

[2] S. Akira, S. Uematsu, and O. Takeuchi, "Pathogen recognition and innate immunity," Cell, vol. 124, no. 4, pp. 783-801, 2006.

[3] X. Cai, Y.-H. Chiu, and Z. J. Chen, "The cGAS-cGAMP-STING pathway of cytosolic DNA sensing and signaling," Molecular Cell, vol. 54, no. 2, pp. 289-296, 2014.

[4] M. Li, Y. Zhou, G. Feng, and S. B. Su, "The critical role of toll-like receptor signaling pathways in the induction and progression of autoimmune disease," Current Molecular Medicine, vol. 9, no. 3, pp. 365-374, 2009.

[5] N. J. Gay and M. Gangloff, "Structure and function of toll receptors and their ligands," Annual Review of Biochemistry, vol. 76, pp. 141-145, 2007.

[6] S. Akira and K. Takeda, "Toll-like receptor signalling," Nature Reviews Immunology, vol. 4, no. 7, pp. 499-511, 2004.

[7] T. Kawai and S. Akira, "TLR signaling," Seminars in Immunology, vol. 19, no. 1, pp. 24-32, 2007.
[8] I. Berglová, J. Krejsek, M. Koláčková, and R. Slezák, "B cell toll-like receptors with respect to the pathogenesis of sjögren's syndrome," Acta Medica (Hradec Kralove, Czech Republic), vol. 54, no. 2, pp. 51-57, 2011.

[9] H. J. Anders, D. Zecher, R. D. Pawar, and P. S. Patole, "Molecular mechanisms of autoimmunity triggered by microbial infection," Arthritis Research Therapy, vol. 7, no. 5, pp. 215-224, 2005.

[10] S. Akira and H. Hemmi, "Recognition of pathogen-associated molecular patterns by TLR family," Immunology Letters, vol. 85, no. 2, pp. 85-95, 2003.

[11] H. Kanzler, F. J. Barrat, E. M. Hessel, and R. L. Coffman, “Therapeutic targeting of innate immunity with Toll-like receptor agonists and antagonists," Nature Medicine, vol. 13, no. 5, pp. 552-559, 2007.

[12] J. Booth, H. Wilson, S. Jimbo, and G. Mutwiri, "Modulation of B cell responses by Toll-like receptors," Cell and Tissue Research, vol. 343, no. 1, pp. 131-140, 2011.

[13] L. M. Skivka and V. V. Pozur, "Responses with participation of toll-like receptors in protective immunity and in pathologic states," Ukrain'skyi Biokhimichnyi Zhurnal, vol. 80, no. 3, pp. 520, 2008.

[14] K. H. G. Mills, "Induction, function and regulation of IL-17producing T cells," European Journal of Immunology, vol. 38, no. 10, pp. 2636-2649, 2008.

[15] Y. Park, S. Park, E. Yoo, D. Kim, and H. Shin, "Association of the polymorphism for toll-like receptor 2 with type 1 diabetes susceptibility," Annals of the New York Academy of Sciences, vol. 1037, pp. 170-174, 2004.

[16] J. Hong, E. Leung, A. G. Fraser, T. R. Merriman, P. Vishnu, and G. W. Krissansen, "TLR2, TLR4 and TLR9 polymorphisms and Crohn's disease in a New Zealand Caucasian cohort," Journal of Gastroenterology and Hepatology, vol. 22, no. 11, pp. 1760-1766, 2007.

[17] B. Serafini, B. Rosicarelli, D. Franciotta et al., "Dysregulated Epstein-Barr virus infection in the multiple sclerosis brain," Journal of Experimental Medicine, vol. 204, no. 12, pp. 28992912, 2007.

[18] I. R. Rifkin, E. A. Leadbetter, L. Busconi, G. Viglianti, and A. Marshak-Rothstein, "Toll-like receptors, endogenous ligands, and systemic autoimmune disease," Immunological Reviews, vol. 204, pp. 27-42, 2005.

[19] E. Andreakos, B. Foxwell, and M. Feldmann, "Is targeting Tolllike receptors and their signaling pathway a useful therapeutic approach to modulating cytokine-driven inflammation?" Immunological Reviews, vol. 202, pp. 250-265, 2004.

[20] A. Marshak-Rothstein, "Toll-like receptors in systemic autoimmune disease," Nature Reviews Immunology, vol. 6, no. 11, pp. 823-835, 2006.

[21] K. H. G. Mills, "TLR-dependent T cell activation in autoimmunity," Nature Reviews Immunology, vol. 11, no. 12, pp. 807-822, 2011.

[22] F. Y. Liew, D. Xu, E. K. Brint, and L. A. J. O’Neill, "Negative regulation of toll-like receptor-mediated immune responses," Nature Reviews Immunology, vol. 5, no. 6, pp. 446-458, 2005.

[23] C. Pasare and R. Medzhitov, "Toll pathway-dependent blockade of $\mathrm{CD} 4{ }^{+} \mathrm{CD} 25^{+} \mathrm{T}$ cell-mediated suppression by dendritic cells," Science, vol. 299, no. 5609, pp. 1033-1036, 2003.

[24] K. W. Moore, R. de Waal Malefyt, R. L. Coffman, and A. O'Garra, "Interleukin-10 and the interleukin-10 receptor," Annual Review of Immunology, vol. 19, pp. 683-765, 2001. 
[25] O. Duramad, K. L. Fearon, J. H. Chan et al., "IL-10 regulates plasmacytoid dendritic cell response to CpG-containing immunostimulatory sequences," Blood, vol. 102, no. 13, pp. 4487-4492, 2003.

[26] M. Farrugia and B. Baron, "Role of regulatory t-cells in oral tolerance and immunotherapy," Biochemistry Physiology: Open Access, vol. 5, no. 199, 7 pages, 2016.

[27] D. M. Underhill, "Collaboration between the innate immune receptors dectin-1, TLRs, and Nods," Immunological Reviews, vol. 219, no. 1, pp. 75-87, 2007.

[28] L. A. J. O'Neill and A. G. Bowie, "The family of five: TIRdomain-containing adaptors in Toll-like receptor signalling," Nature Reviews Immunology, vol. 7, no. 5, pp. 353-364, 2007.

[29] K. Honda, H. Yanai, H. Negishi et al., "IRF-7 is the master regulator of type-I interferon-dependent immune responses," Nature, vol. 434, no. 7034, pp. 772-777, 2005.

[30] J. Lee, J. W. Sohn, Y. Zhang, K. W. Leong, D. Pisetsky, and B. A. Sullenger, "Nucleic acid-binding polymers as antiinflammatory agents," Proceedings of the National Academy of Sciences of the United States of America, vol. 108, no. 34, pp. 14055-14060, 2011.

[31] O. Adachi, T. Kawai, K. Takeda et al., "Targeted disruption of the MyD88 gene results in loss of IL-1- and IL-18-mediated function," Immunity, vol. 9, no. 1, pp. 143-150, 1998.

[32] T. Horng, G. M. Barton, R. A. Flavell, and R. Medzhitov, “The adaptor molecule TIRAP provides signalling specificity for Tolllike receptors," Nature, vol. 420, no. 6913, pp. 329-333, 2002.

[33] J. C. Kagan and R. Medzhitov, "Phosphoinositide-mediated adaptor recruitment controls Toll-like receptor signaling," Cell, vol. 125, no. 5, pp. 943-955, 2006.

[34] L. Sun, L. Deng, C.-K. Ea, Z.-P. Xia, and Z. J. Chen, “The TRAF6 ubiquitin ligase and TAK1 kinase mediate IKK activation by BCL10 and MALT1 in T lymphocytes," Molecular Cell, vol. 14, no. 3, pp. 289-301, 2004.

[35] M. Yamamoto, S. Sato, H. Hemmi et al., "TRAM is specifically involved in the Toll-like receptor 4-mediated MyD88independent signaling pathway," Nature Immunology, vol. 4, no. 11, pp. 1144-1150, 2003.

[36] S.-C. Lin, Y.-C. Lo, and H. Wu, "Helical assembly in the MyD88IRAK4-IRAK2 complex in TLR/IL-1R signalling," Nature, vol. 465, no. 7300, pp. 885-890, 2010.

[37] Z. Jiang, J. Ninomiya-Tsuji, Y. Qian, K. Matsumoto, and X. Li, "Interleukin-1 (IL-1) receptor-associated kinase-dependent IL1-induced signaling complexes phosphorylate TAK1 and TAB2 at the plasma membrane and activate TAK1 in the cytosol," Molecular and Cellular Biology, vol. 22, no. 20, pp. 7158-7167, 2002.

[38] C. Kollewe, A.-C. Mackensen, D. Neumann et al., "Sequential autophosphorylation steps in the interleukin-1 receptorassociated kinase-1 regulate its availability as an adapter in interleukin-1 signaling," The Journal of Biological Chemistry, vol. 279, no. 7, pp. 5227-5236, 2004.

[39] Z. J. Chen, "Ubiquitination in signaling to and activation of IKK," Immunological Reviews, vol. 246, no. 1, pp. 95-106, 2012.

[40] A. A. Ajibade, H. Y. Wang, and R.-F. Wang, "Cell type-specific function of TAK1 in innate immune signaling," Trends in Immunology, vol. 34, no. 7, pp. 307-316, 2013.

[41] T. Kawai and S. Akira, "The role of pattern-recognition receptors in innate immunity: update on toll-like receptors," Nature Immunology, vol. 11, no. 5, pp. 373-384, 2010.
[42] L. Alexopoulou, A. C. Holt, R. Medzhitov, and R. A. Flavell, "Recognition of double-stranded RNA and activation of NF- $\kappa$ B by toll-like receptor 3," Nature, vol. 413, no. 6857, pp. 732-738, 2001.

[43] S. S. Diebold, T. Kaisho, H. Hemmi, S. Akira, and C. Reis E Sousa, "Innate antiviral responses by means of TLR7-mediated recognition of single-stranded RNA," Science, vol. 303, no. 5663, pp. 1529-1531, 2004.

[44] F. Heil, H. Hemmi, H. Hochrein et al., "Species-specific recognition of single-stranded RNA via toll-like receptor 7 and 8," Science, vol. 303, no. 5663, pp. 1526-1529, 2004.

[45] J. M. Lund, L. Alexopoulou, A. Sato et al., "Recognition of single-stranded RNA viruses by toll-like receptor 7," Proceedings of the National Academy of Sciences of the United States of America, vol. 101, no. 15, pp. 5598-5603, 2004.

[46] H. Hemmi, O. Takeuchi, T. Kawai et al., "A Toll-like receptor recognizes bacterial DNA," Nature, vol. 408, no. 6813, pp. 740$745,2000$.

[47] T. Kawai and S. Akira, "Toll-like receptor and RIG-1-like receptor signaling," Annals of the New York Academy of Sciences, vol. 1143, pp. 1-20, 2008.

[48] K. Karikó, H. Ni, J. Capodici, M. Lamphier, and D. Weissman, "mRNA is an endogenous ligand for toll-like receptor 3," The Journal of Biological Chemistry, vol. 279, no. 13, pp. 12542-12550, 2004.

[49] L. Rönnblom and G. V. Alm, "Systemic lupus erythematosus and the type I interferon system," Arthritis Research Therapy, vol. 5, pp. 68-75, 2003.

[50] F. J. Barrat, T. Meeker, J. Gregorio et al., "Nucleic acids of mammalian origin can act as endogenous ligands for Tolllike receptors and may promote systemic lupus erythematosus," Journal of Experimental Medicine, vol. 202, no. 8, pp. 1131-1139, 2005.

[51] E. A. Leadbetter, I. R. Rifkin, A. M. Hohlbaum, B. C. Beaudette, M. J. Shlomchik, and A. Marshak-Rothstein, "Chromatin-IgG complexes activate B cells by dual engagement of IgM and Tolllike receptors," Nature, vol. 416, no. 6881, pp. 603-607, 2002.

[52] C. M. Lau, C. Broughton, A. S. Tabor et al., "RNA-associated autoantigens activate B cells by combined B cell antigen receptor/Toll-like receptor 7 engagement," Journal of Experimental Medicine, vol. 202, no. 9, pp. 1171-1177, 2005.

[53] U. Båve, M. Magnusson, M.-L. Eloranta, A. Perers, G. V. Alm, and L. Rönnblom, "Fc $\gamma$ RIIa is expressed on natural IFN- $\alpha$ producing cells (plasmacytoid dendritic cells) and is required for the IFN- $\alpha$ production induced by apoptotic cells combined with lupus IgG," The Journal of Immunology, vol. 171, no. 6, pp. 3296-3302, 2003.

[54] T. K. Means, E. Latz, F. Hayashi, M. R. Murali, D. T. Golenbock, and A. D. Luster, "Human lupus autoantibody-DNA complexes activate DCs through cooperation of CD32 and TLR9," The Journal of Clinical Investigation, vol. 115, no. 2, pp. 407-417, 2005.

[55] J. Vollmer, S. Tluk, C. Schmitz et al., "Immune stimulation mediated by autoantigen binding sites within small nuclear RNAs involves Toll-like receptors 7 and 8," The Journal of Experimental Medicine, vol. 202, no. 11, pp. 1575-1585, 2005.

[56] B. L. Lee, J. E. Moon, J. H. Shu et al., "UNC93B1 mediates differential trafficking of endosomal TLRs," eLife, vol. 2, Article ID e00291, 2013.

[57] R. Fukui, S.-I. Saitoh, A. Kanno et al., "Unc93B1 restricts systemic lethal inflammation by orchestrating toll-like receptor 7 and 9 trafficking," Immunity, vol. 35, no. 1, pp. 69-81, 2011. 
[58] H. Itoh, M. Tatematsu, A. Watanabe et al., "UNC93B1 physically associates with human TLR8 and regulates TLR8-mediated signaling," PLoS ONE, vol. 6, no. 12, Article ID e28500, 2011.

[59] R. Fukui, S.-I. Saitoh, F. Matsumoto et al., "Unc93B1 biases Toll-like receptor responses to nucleic acid in dendritic cells toward DNA- but against RNA-sensing," Journal of Experimental Medicine, vol. 206, no. 6, pp. 1339-1350, 2009.

[60] B. Desnues, A. B. Macedo, A. Roussel-Queval et al., "TLR8 on dendritic cells and TLR9 on B cells restrain TLR7-mediated spontaneous autoimmunity in C57BL/6 mice," Proceedings of the National Academy of Sciences of the United States of America, vol. 111, no. 4, pp. 1497-1502, 2014.

[61] H. Qi, T. L. Denning, and L. Soong, "Differential induction of interleukin-10 and interleukin-12 in dendritic cells by microbial Toll-like receptor activators and skewing of T-cell cytokine profiles," Infection and Immunity, vol. 71, no. 6, pp. 3337-3342, 2003.

[62] S. C. Eisenbarth, D. A. Piggott, J. W. Huleatt, I. Visintin, C. A. Herrick, and K. Bottomly, "Lipopolysaccharide-enhanced, toll-like receptor 4-dependent T helper cell type 2 responses to inhaled antigen," Journal of Experimental Medicine, vol. 196, no. 12, pp. 1645-1651, 2002.

[63] F. Re and J. L. Strominger, "Toll-like receptor 2 (TLR2) and TLR4 differentially activate human dendritic cells," The Journal of Biological Chemistry, vol. 276, no. 40, pp. 37692-37699, 2001.

[64] B. Martin, K. Hirota, D. J. Cua, B. Stockinger, and M. Veldhoen, "Interleukin-17-producing $\gamma \delta \mathrm{T}$ cells selectively expand in response to pathogen products and environmental signals," Immunity, vol. 31, no. 2, pp. 321-330, 2009.

[65] J. M. Reynolds, B. P. Pappu, J. Peng et al., “Toll-like receptor 2 signaling in $\mathrm{CD}^{+} \mathrm{T}$ lymphocytes promotes $\mathrm{T}$ helper 17 responses and regulates the pathogenesis of autoimmune disease," Immunity, vol. 32, no. 5, pp. 692-702, 2010.

[66] M. Komai-Koma, L. Jones, G. S. Ogg, D. Xu, and F. Y. Liew, "TLR2 is expressed activated T cells as a costimulatory receptor," Proceedings of the National Academy of Sciences of the United States of America, vol. 101, no. 9, pp. 3029-3034, 2004.

[67] B. C. Mercier, A. Cottalorda, C. A. Coupet, J. Marvel, and N. Bonnefoy-Bérard, "TLR2 engagement on CD8 T cells enables generation of functional memory cells in response to a suboptimal TCR signal," The Journal of Immunology, vol. 182, no. 4, pp. 1860-1867, 2009.

[68] S. T. Smiley, J. A. King, and W. W. Hancock, "Fibrinogen stimulates macrophage chemokine secretion through toll-like receptor 4," Journal of Immunology, vol. 167, no. 5, pp. 2887$2894,2001$.

[69] A. Biragyn, P. A. Ruffini, C. A. Leifer et al., “Toll-like receptor 4dependent activation of dendritic cells by $\beta$-defensin 2 ," Science, vol. 298, no. 5595, pp. 1025-1029, 2002.

[70] M. Raska and E. Weigl, "Heat shock proteins in autoimmune diseases," Biomedical Papers, vol. 149, no. 2, pp. 243-249, 2005.

[71] N. M. Green and A. Marshak-Rothstein, "Toll-like receptor driven B cell activation in the induction of systemic autoimmunity," Seminars in Immunology, vol. 23, no. 2, pp. 106-112, 2011.

[72] M. Ehlers, H. Fukuyama, T. L. McGaha, A. Aderem, and J. V. Ravetch, "TLR9/MyD88 signaling is required for class switching to pathogenic IgG2a and 2b autoantibodies in SLE," Journal of Experimental Medicine, vol. 203, no. 3, pp. 553-561, 2006.

[73] J. R. Groom, C. A. Fletcher, S. N. Walters et al., "BAFF and MyD88 signals promote a lupuslike disease independent of $\mathrm{T}$ cells," Journal of Experimental Medicine, vol. 204, no. 8, pp. 1959-1971, 2007.
[74] S. Becker-Herman, A. Meyer-Bahlburg, M. A. Schwartz et al., "WASp-deficient B cells play a critical, cell-intrinsic role in triggering autoimmunity," Journal of Experimental Medicine, vol. 208, no. 10, pp. 2033-2042, 2011.

[75] A. B. Begovich, V. E. H. Carlton, L. A. Honigberg et al., "A missense single-nucleotide polymorphism in a gene encoding a protein tyrosine phosphatase (PTPN22) is associated with rheumatoid arthritis," American Journal of Human Genetics, vol. 75, no. 2, pp. 330-337, 2004.

[76] R. M. Plenge, C. Cotsapas, L. Davies et al., "Two independent alleles at 6q23 associated with risk of rheumatoid arthritis," Nature Genetics, vol. 39, no. 12, pp. 1477-1482, 2007.

[77] S. M. Sacre, E. Andreakos, S. Kiriakidis et al., "The toll-like receptor adaptor proteins MyD88 and Mal/TIRAP contribute to the inflammatory and destructive processes in a human model of rheumatoid arthritis," American Journal of Pathology, vol. 170, no. 2, pp. 518-525, 2007.

[78] M. H. Hoffmann, K. Skriner, S. Herman et al., "Nucleic acidstimulated antigen-presenting cells trigger $\mathrm{T}$ cells to induce disease in a rat transfer model of inflammatory arthritis," Journal of Autoimmunity, vol. 36, no. 3-4, pp. 288-300, 2011.

[79] S. J. Creely, P. G. McTernan, C. M. Kusminski et al., "Lipopolysaccharide activates an innate immune system response in human adipose tissue in obesity and type 2 diabetes," American Journal of Physiology-Endocrinology and Metabolism, vol. 292, no. 3, pp. E740-E747, 2007.

[80] M. F. Denny, S. Thacker, H. Mehta et al., "Interferon- $\alpha$ promotes abnormal vasculogenesis in lupus: a potential pathway for premature atherosclerosis," Blood, vol. 110, no. 8, pp. 2907-2915, 2007.

[81] R. Lande, J. Gregorio, V. Facchinetti et al., "Plasmacytoid dendritic cells sense self-DNA coupled with antimicrobial peptide," Nature, vol. 449, no. 7162, pp. 564-569, 2007.

[82] S. Rakoff-Nahoum and R. Medzhitov, "Toll-like receptors and cancer," Nature Reviews Cancer, vol. 9, no. 1, pp. 57-63, 2009.

[83] C. Guiducci, G. Ott, J. H. Chan et al., "Properties regulating the nature of the plasmacytoid dendritic cell response to Toll-like receptor 9 activation," The Journal of Experimental Medicine, vol. 203, no. 8, pp. 1999-2008, 2006.

[84] K. Honda, Y. Ohba, H. Yanai et al., "Spatiotemporal regulation of MyD88-IRF-7 signalling for robust type-I interferon induction," Nature, vol. 434, no. 7036, pp. 1035-1040, 2005.

[85] S. Fasciano and L. Li, "Intervention of toll-like receptorsmediated human innate immunity and inflammation by synthetic compunds and naturally occurring products," Current Medicinal Chemistry, vol. 13, no. 12, pp. 1389-1395, 2006.

[86] T. Du, Z.-G. Zhou, S. You et al., "Modulation of monocyte hyperresponsiveness to TLR ligands by 1,25-dihydroxy-vitamin D3 from LADA and T2DM," Diabetes Research and Clinical Practice, vol. 83, no. 2, pp. 208-214, 2009.

[87] S. Sun, N. L. Rao, J. Venable, R. Thurmond, and L. Karlsson, "TLR7/9 antagonists as the rapeutics for immune-mediated inflammatory disorders," Inflammation Allergy-Drug Targets, vol. 6, no. 4, pp. 223-235, 2007.

[88] M. Rutz, J. Metzger, T. Gellert et al., “Toll-like receptor 9 binds single-stranded CpG-DNA in a sequence- and $\mathrm{pH}$-dependent manner," European Journal of Immunology, vol. 34, no. 9, pp. 2541-2550, 2004.

[89] A. M. Krieg and J. Vollmer, "Toll-like receptors 7, 8, and 9: linking innate immunity to autoimmunity," Immunological Reviews, vol. 220, no. 1, pp. 251-269, 2007. 
[90] E. D. Papadimitraki, G. K. Bertsias, and D. T. Boumpas, "Toll like receptors and autoimmunity: a critical appraisal," Journal of Autoimmunity, vol. 29, no. 4, pp. 310-318, 2007.

[91] D. Zipris, E. Lien, A. Nair et al., “TLR9-signaling pathways are involved in Kilham rat virus-induced autoimmune diabetes in the biobreeding diabetes-resistant rat," The Journal of Immunology, vol. 178, no. 2, pp. 693-701, 2007.

[92] T. Hayashi, C. S. Gray, M. Chan et al., "Prevention of autoimmune disease by induction of tolerance to toll-like receptor 7," Proceedings of the National Academy of Sciences of the United States of America, vol. 106, no. 8, pp. 2764-2769, 2009.

[93] M. Loiarro, F. Capolunghi, N. Fantò et al., "Inhibition of MyD88 dimerization and recruitment of IRAK1 and IRAK4 by a novel peptidomimetic compound," Journal of Leukocyte Biology, vol. 82, no. 4, pp. 801-810, 2007.

[94] T. Bartfai, M. M. Behrens, S. Gaidarova, J. Pemberton, A. Shivanyuk, and J. Rebek Jr., "A low molecular weight mimic of the Toll/IL-1 receptor/resistance domain inhibits IL-1 receptormediated responses," Proceedings of the National Academy of Sciences of the United States of America, vol. 100, no. 13, pp. 79717976, 2003.

[95] K. W. Song, F. X. Talamas, R. T. Suttmann et al., "The kinase activities of interleukin-1 receptor associated kinase (IRAK)-1 and 4 are redundant in the control of inflammatory cytokine expression in human cells," Molecular Immunology, vol. 46, no. 7, pp. 1458-1466, 2009.

[96] B. Skaug, J. Chen, F. Du, J. He, A. Ma, and Z. J. Chen, "Direct, noncatalytic mechanism of IKK inhibition by A20," Molecular Cell, vol. 44, no. 4, pp. 559-571, 2011.

[97] J.-M. Yuk, D.-M. Shin, H.-M. Lee et al., "The orphan nuclear receptor SHP acts as a negative regulator in inflammatory signaling triggered by Toll-like receptors," Nature Immunology, vol. 12, no. 8, pp. 742-751, 2011.

[98] T. Kondo, T. Kawai, and S. Akira, "Dissecting negative regulation of Toll-like receptor signaling," Trends in Immunology, vol. 33, no. 9, pp. 449-458, 2012.

[99] M. Shi, W. Deng, E. Bi et al., "TRIM30 $\alpha$ negatively regulates TLR-mediated $\mathrm{NF} \kappa \mathrm{B}$ activation by targeting TAB2 and TAB3 for degradation," Nature Immunology, vol. 9, no. 4, pp. 369-377, 2008.

[100] T. Saitoh, A. Tun-Kyi, A. Ryo et al., "Negative regulation of interferon-regulatory factor 3-dependent innate antiviral response by the prolyl isomerase Pinl," Nature Immunology, vol. 7, no. 6, pp. 598-605, 2006.

[101] E. M. Palsson-McDermott, S. L. Doyle, A. F. McGettrick et al., "TAG, a splice variant of the adaptor TRAM, negatively regulates the adaptor MyD88-independent TLR4 pathway," Nature Immunology, vol. 10, no. 6, pp. 579-586, 2009.

[102] C. Han, J. Jin, S. Xu, H. Liu, N. Li, and X. Cao, "Integrin CD11b negatively regulates TLR-triggered inflammatory responses by activating Syk and promoting degradation of MyD88 and TRIF via Cbl-b," Nature Immunology, vol. 11, no. 8, pp. 734-742, 2010.

[103] M. Carty, R. Goodbody, M. Schröder, J. Stack, P. N. Moynagh, and A. G. Bowie, "The human adaptor SARM negatively regulates adaptor protein TRIF-dependent Toll-like receptor signaling," Nature Immunology, vol. 7, no. 10, pp. 1074-1081, 2006.

[104] N. Kayagaki, Q. Phung, S. Chan et al., "DUBA: a deubiquitinase that regulates type I interferon production," Science, vol. 318, no. 5856, pp. 1628-1632, 2007.

[105] A. Asari, T. Kanemitsu, and H. Kurihara, "Oral administration of high molecular weight hyaluronan $(900 \mathrm{kDa})$ controls immune system via toll-like receptor 4 in the intestinal epithelium," The Journal of Biological Chemistry, vol. 285, no. 32, pp. 24751-24758, 2010.

[106] K. Matsushita, O. Takeuchi, D. M. Standley et al., "Zc3h12a is an RNase essential for controlling immune responses by regulating mRNA decay," Nature, vol. 458, no. 7242, pp. 1185-1190, 2009.

[107] O. Duramad, K. L. Fearon, B. Chang et al., "Inhibitors of TLR9 act on multiple cell subsets in mouse and man in vitro and prevent death in vivo from systemic inflammation," The Journal of Immunology, vol. 174, no. 9, pp. 5193-5200, 2005.

[108] A. M. Krieg, T. Wu, R. Weeratna et al., "Sequence motifs in adenoviral DNA block immune activation by stimulatory CpG motifs," Proceedings of the National Academy of Sciences of the United States of America, vol. 95, no. 21, pp. 12631-12636, 1998.

[109] H. Yamada, I. Gursel, F. Takeshita et al., "Effect of suppressive DNA on CpG-induced immune activation," The Journal of Immunology, vol. 169, no. 10, pp. 5590-5594, 2002.

[110] F.-G. Zhu, C. F. Reich, and D. S. Pisetsky, "Inhibition of murine dendritic cell activation by synthetic phosphorothioate oligodeoxynucleotides," Journal of Leukocyte Biology, vol. 72, no. 6, pp. 1154-1163, 2002.

[111] L. L. Stunz, P. Lenert, D. Peckham et al., "Inhibitory oligonucleotides specifically block effects of stimulatory CpG oligonucleotides in B cells," European Journal of Immunology, vol. 32, pp. 1212-1222, 2002.

[112] P. P. Ho, P. Fontoura, P. J. Ruiz, L. Steinman, and H. Garren, "An immunomodulatory GpG oligonucleotide for the treatment of autoimmunity via the innate and adaptive immune systems," Journal of Immunology, vol. 171, no. 9, pp. 4920-4926, 2003.

[113] I. Gursel, M. Gursel, H. Yamada, K. J. Ishii, F. Takeshita, and D. M. Klinman, "Repetitive elements in mammalian telomeres suppress bacterial DNA-induced immune activation," The Journal of Immunology, vol. 171, no. 3, pp. 1393-1400, 2003.

[114] R. A. Zeuner, K. J. Ishii, M. J. Lizak et al., "Reduction of CpG-induced arthritis by suppressive oligodeoxynucleotides," Arthritis Rheumatology, vol. 46, pp. 2219-2224, 2002.

[115] L. Dong, S. Ito, K. J. Ishii, and D. M. Klinman, "Suppressive oligonucleotides protect against collagen-induced arthritis in mice," Arthritis Rheumatology, vol. 50, pp. 1686-1689, 2004.

[116] F. Grela, A. Aumeunier, E. Bardel et al., “The TLR7 agonist R848 alleviates allergic inflammation by targeting invariant NKT cells to produce IFN- $\gamma$," The Journal of Immunology, vol. 186, no. 1, pp. 284-290, 2011.

[117] A. M. Krieg, S. M. Efler, M. Wittpoth, M. J. Al Adhami, and H. L. Davis, "Induction of systemic TH1-like innate immunity in normal volunteers following subcutaneous but not intravenous administration of CPG 7909, a synthetic B-class CpG oligodeoxynucleotide TLR9 agonist," Journal of Immunotherapy, vol. 27, no. 6, pp. 460-471, 2004.

[118] J. W. Friedberg, H. Kim, M. McCauley et al., "Combination immunotherapy with a CpG oligonucleotide (1018 ISS) and rituximab in patients with non-Hodgkin lymphoma: increased interferon- $\alpha / \beta$-inducible gene expression, without significant toxicity," Blood, vol. 105, no. 2, pp. 489-495, 2005.

[119] G. M. Gauvreau, E. M. Hessel, L.-P. Boulet, R. L. Coffman, and P. M. O'Byrne, "Immunostimulatory sequences regulate interferon-inducible genes but not allergic airway responses," American Journal of Respiratory and Critical Care Medicine, vol. 174, no. 1, pp. 15-20, 2006.

[120] L. Bennett, A. K. Palucka, E. Arce et al., "Interferon and granulopoiesis signatures in systemic lupus erythematosus blood," 
The Journal of Experimental Medicine, vol. 197, no. 6, pp. 711723, 2003.

[121] E. C. Baechler, F. M. Batliwalla, G. Karypis et al., "Interferoninducible gene expression signature in peripheral blood cells of patients with severe lupus," Proceedings of the National Academy of Sciences of the United States of America, vol. 100, no. 5, pp. 2610-2615, 2003.

[122] E. Monnet, L. Shang, G. Lapeyre et al., "Translational data and phase 1 study results of a new monoclonal antibody targeting Toll like receptor 4 (TLR4) developed for rheumatoid arthritis (RA) treatment with a potential for personalized medicine," Arthritis \& Rheumatology, vol. 67, abstract 1661, pp. 2051-2052, 2015.

[123] Y.-W. Wu, W. Tang, and J.-P. Zuo, “Toll-like receptors: Potential targets for lupus treatment," Acta Pharmacologica Sinica, vol. 36, no. 12, pp. 1395-1407, 2015. 


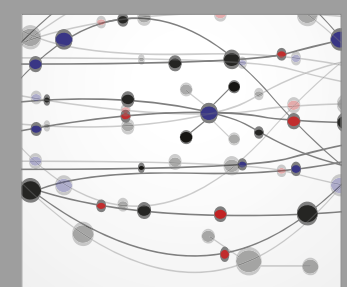

The Scientific World Journal
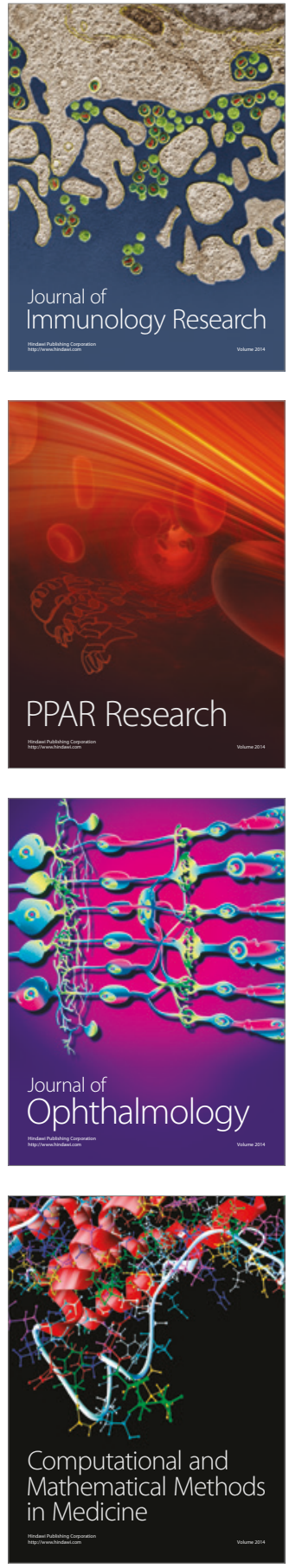

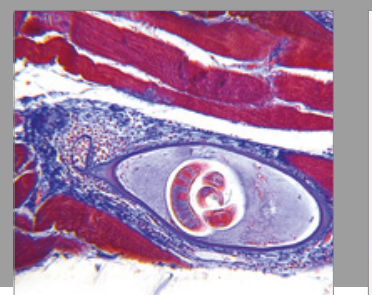

Gastroenterology Research and Practice
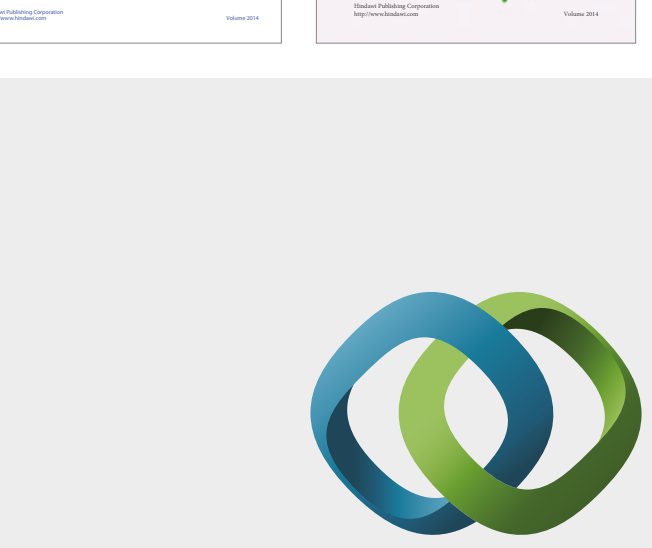

\section{Hindawi}

Submit your manuscripts at

https://www.hindawi.com
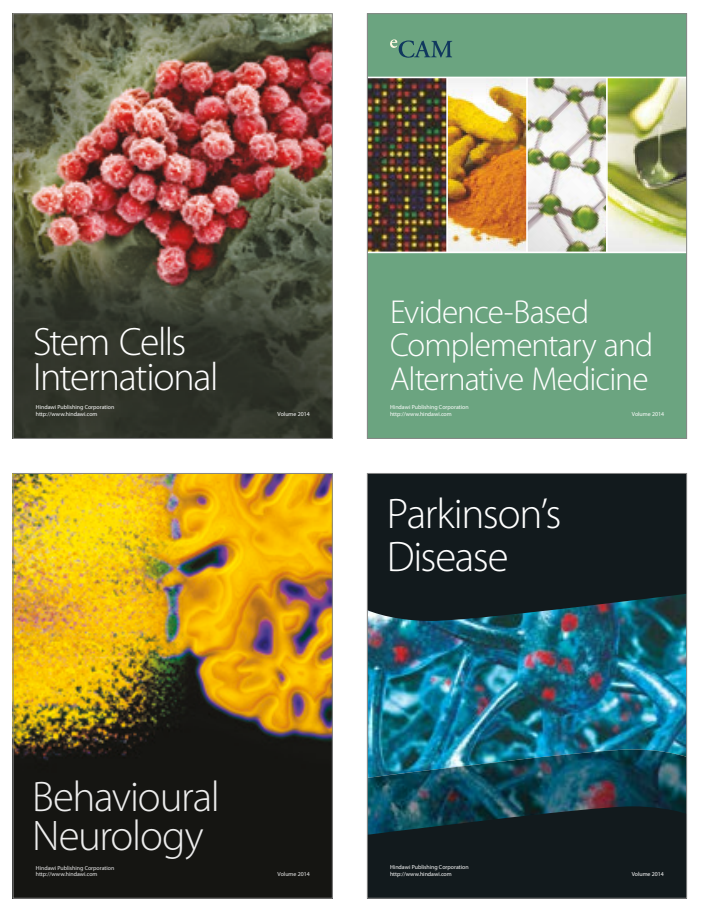
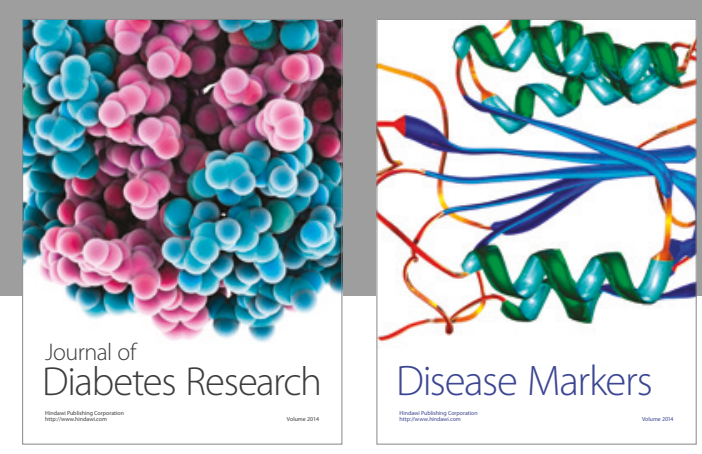

Disease Markers
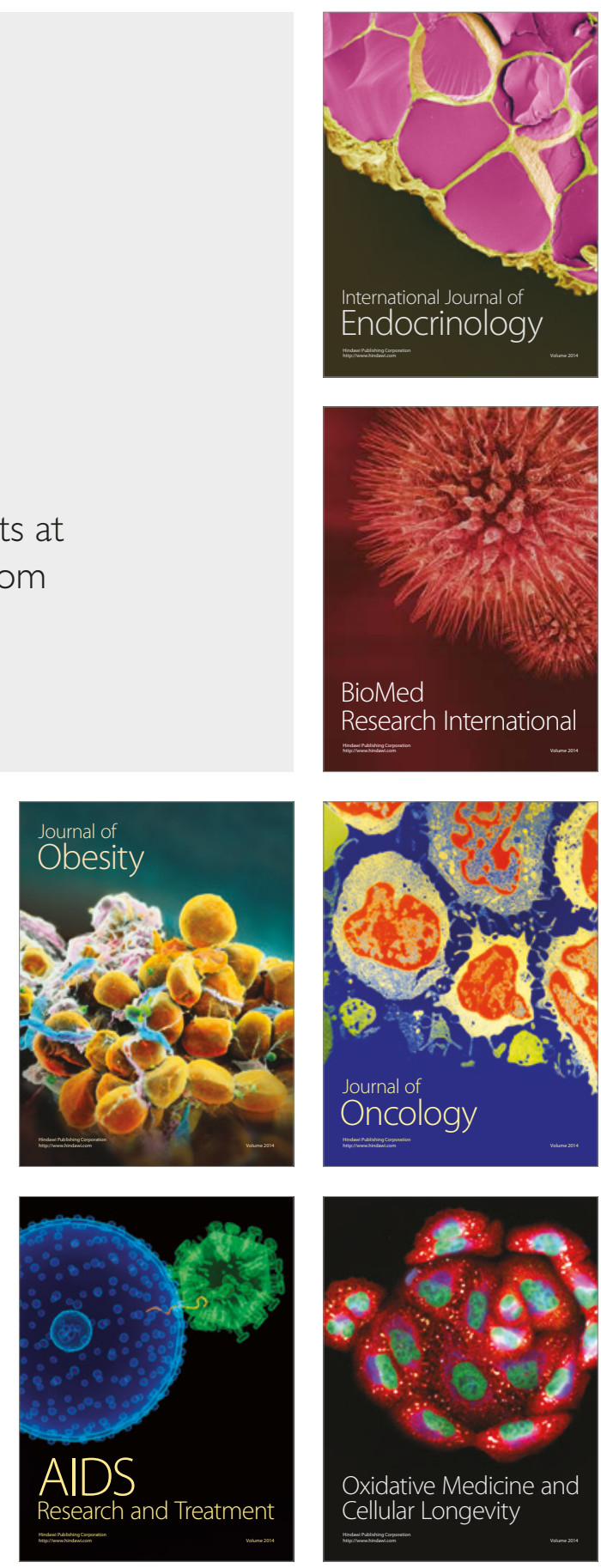